\title{
Methodology for electrothermal characterization of permanent magnet motor and its equivalent to coiled rotor
}

\author{
Souhir Tounsi \\ School of Electronics and Telecommunications of Sfax, Sfax University, Sfax, Tunisia \\ Email address: \\ souhir.tounsi@isecs.rnu.tn
}

To cite this article:

Souhir Tounsi. Methodology for Electrothermal Characterization of Permanent Magnet Motor and Its Equivalent to Coiled Rotor. American Journal of Electrical Power and Energy Systems. Special Issue: Design, Optimization and Control of Electric Vehicles: (DOCEV).

Vol. 4, No. 2-1, 2015, pp. 8-16. doi: 10.11648/j.epes.s.2015040201.12

\begin{abstract}
In this paper, we present a methodology for electrothermal characterization of two configurations: permanent magnet motor and its equivalent to wound rotor. This modeling approach is in the aim to evaluating the different temperatures in different active parts of the two configurations, to choose the type and characteristics of the cooling system to use. A comparative study between the two solutions is presented.
\end{abstract}

Keywords: Electrothermal, Modeling, Nodal Method, Simulation, Coiled Motor, Permanents Magnets Motor

\section{Introduction}

The main objective of the electrothermal modeling of thermal stresses is to respect the good working of the electric motor. In fact, exceeding the melting temperature of the coils insulation set at $100^{\circ} \mathrm{C}$ leads to the deterioration of the coils and subsequently damage the motor. In addition, knowledge of different temperatures in the active areas of the engine allows firstly to take into account the change of the B-H magnets characteristic (critical temperature is not to exceed $200^{\circ} \mathrm{C}$ for Sm-Co magnet), and secondly the change in resistance phases of electric motor, strongly influencing the electrical, magnetic and mechanical behavior of engine. This knowledge temperatures determines the nature and power of the cooling system to integrate in the two engine selected configurations. The fisrt configuration is permanent magnets synchrnous motor (PMSM) and the second is a coiled rotor synchronous motor (CRSM). In this context, we study the two cases of motors to choose the most efficient and consistent with a cooling system the least powerful and consequentely the least expensive.

We set a goal to not exceed the limits of the following temperatures:

$200^{\circ} \mathrm{C}$ for permanent magnets (Sm-Co).

$100^{\circ} \mathrm{C}$ for the insulator coil.

This survey must succeed to the choice of the structure of the motor compatible to the least expensive cooling system.

\section{Choice of Modeling Approach}

Conventional analytical methods, describes heat transfer with an acceptable complexity. However these methods require precise knowledge of many coefficients (thermal conductivity, heat transfer coefficient, emissivity) that's often difficult to obtain.

Finite elements methods require an important memory resources and computation time. They are therefore not compatible with our approach should allow to model a magnetic component in its environment ie part of a chain of power. In addition, the model developed should make account of all the phenomena involved in a magnetic component (electric phenomena, magnetic and thermal).

The nodal method provides better accuracy compromised results and simulation time. It is therefore compatible to optimization approaches such as the performance of electric vehicle. It seems however best suited to our concerns and lends itself well to an experimental approach. The component to be modeled is divided into insulated areas interconnected by a thermal resistance, the center of a zone is called node. A thermal capacity and a heat source are associated with each zone. A system of differential equations is obtained by writing the heat balance at the various nodes. A first approximation is to consider thermal resistance as constant (for better accuracy thermal resistances can be modeled using analytical relations).

For the components of our synchronous motor, the 
equivalent circuit is limited to a few resistors and capacitors whose values can be obtained by calculation. This method meets our specifications [1].

\section{Nodal Thermal Model of PMSM and CRSM Structures}

The system to be modeled is a synchronous electric motor with axial flux and permanent magnet, or with a coiled rotor (Figure 1). For the two configurations the stator is with same structure and mechanical, electrical and magnetic characteristics are equivalent.

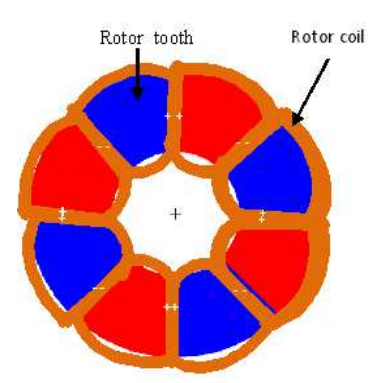

(a) Coiled rotor

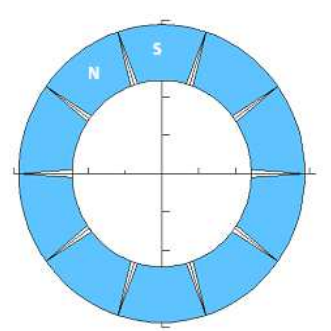

(c) Permanent magnet rotor

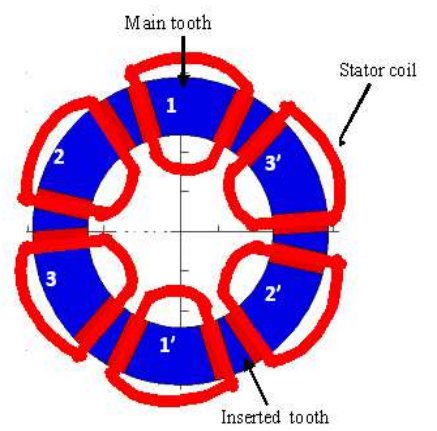

(b) Same stator

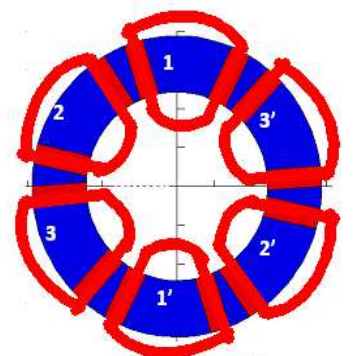

(d) Same stator
Figure 1. PMSM and CRSM equivalents structures.

The 3 D structure of PMSM is illustrated by figure 2 .

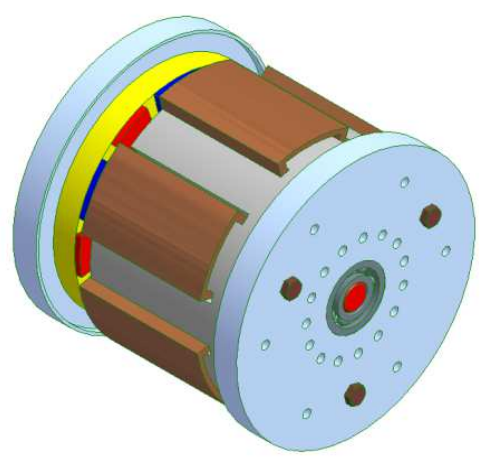

Figure 2. 3 D structure of PMSM

\subsection{Assumptions Used for Modeling}

We recall firstly our assumptions about thermal modeling of magnetic components to justify the principles of selected measures that lead to the measurement of average temperatures. Temperatures are assumed uniform in the material and in the different coils.

We consider an ambient temperature of $27^{\circ} \mathrm{C}$ and we assume a maximum permissible temperature rise of $100^{\circ} \mathrm{C}$ for the stator winding and the insulation. This warming-up is determined by the temperature holding of the conductors and the slots bottom insulators. at the same way, the maximum warming-up of the magnets ( $\mathrm{Sm}-\mathrm{Co})$ must be taken in account and we admit a warming-up of the order of $200{ }^{\circ} \mathrm{C}$. In the context of our model, we consider only perfect contacts, and their conduction resistances are low and broken into account in the thermal model of the PMSM and CRSM.

The heat exchange is assumed in the axial direction, because the length of the two structures in this direction is much lower than that in the radial direction, in addition heat exchange sections perpendicular to the axis of the motor is much greater than those radials [2].

\subsection{Heat Transfer in the PMSM and CRSM Structures}

Heat transfer in the PMSM is illustrated by the following Figure 3:

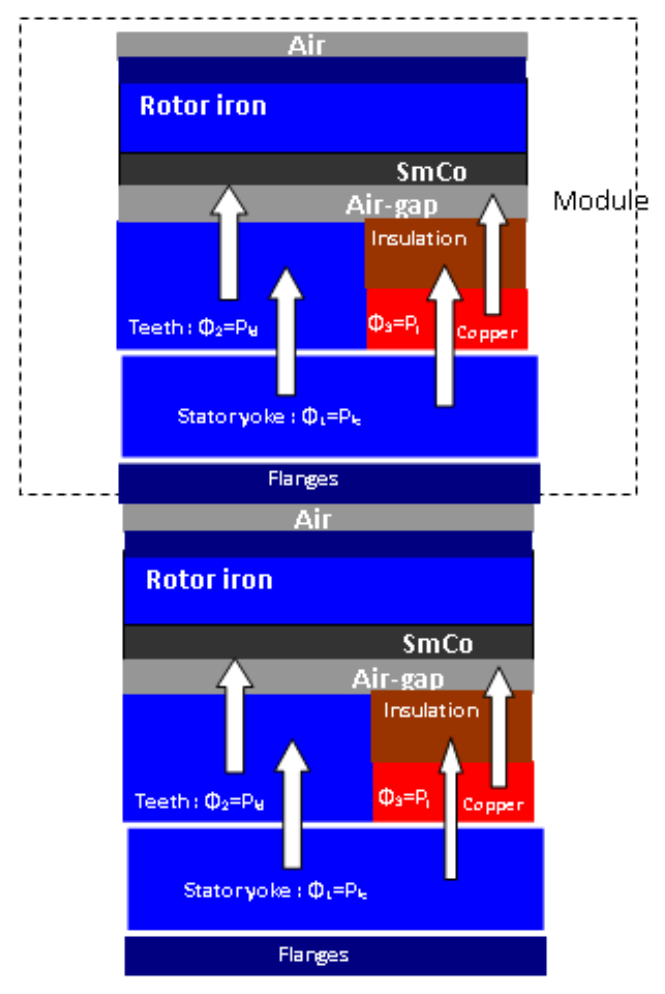

Figure 3. The heat transfer in the PMSM.

The heat transfer in the CRSM is illustrated by the figure 4 [3]: 


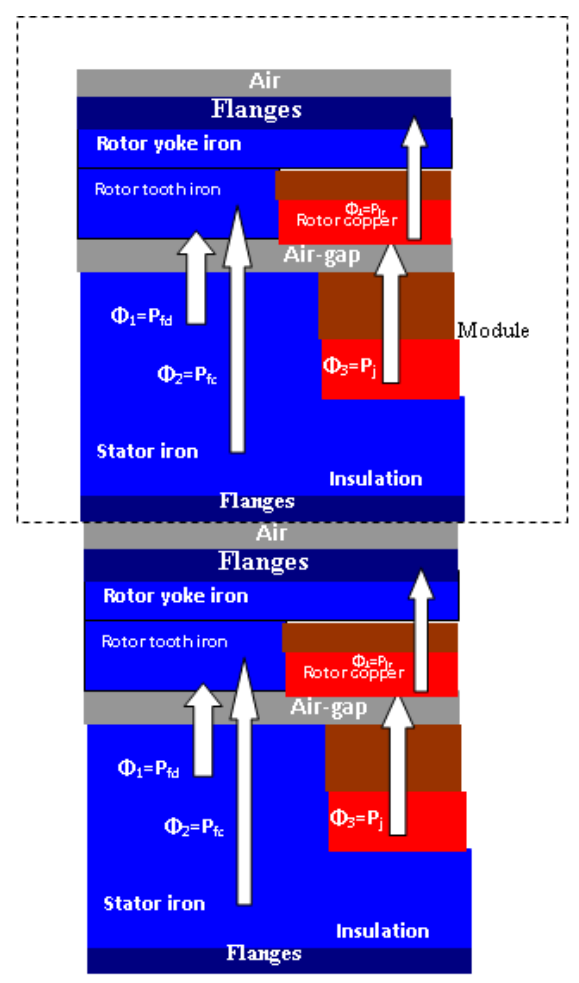

\section{Transient Thermal Model}

We selected a model using thermal-electrical analogy. In order to simplify the model, we have the following assumptions:

- Uniform heat generation.

- Uniformity of physical properties across the element.

- Uniformity of the exchanges on each of the faces.

The machine is divided into simple volume elements exchanging heat between them by conduction or convection. Copper losses include slots losses and end winding losses. The transien thermal model of the PMSM structure can then be represented by an analog electrical network, as described in figure 5 [1], [2], [3], [4] and [5].

The transient thermal model of the CRSM structure is represented by an analog electrical network, as described in figure 6.

Figure 4. The heat transfer in the CRSM.

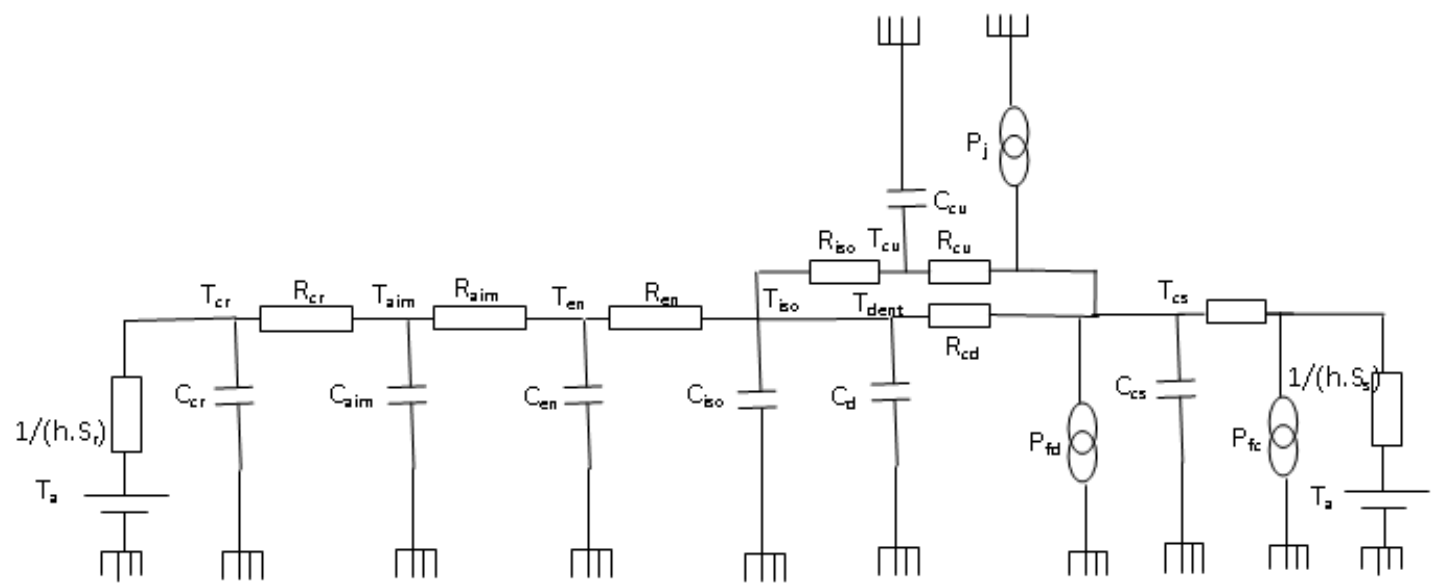

Figure 5. Transient thermal model of the PMSM actuator.

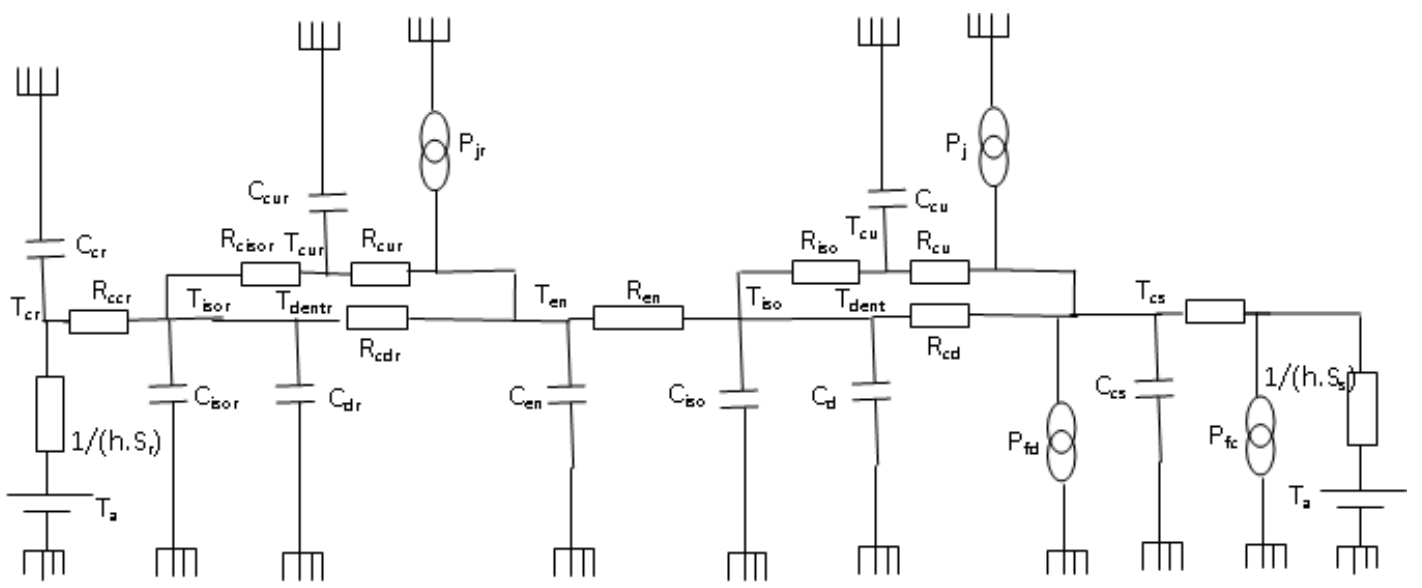

Figure 6. Transient thermal model of the CRSM actuator. 
For the models presented in figure 5 and 6, we define two isothermal zones constituted by the magnetic material on the one hand and by the winding on the other hand.

Previously defined areas are warm seat due to copper losses and iron losses.

$\mathrm{P}_{\mathrm{j}}, \mathrm{P}_{\mathrm{fc}}$ and $\mathrm{P}_{\mathrm{fd}}$ corresponding respectively to the total losses in the coils, in the stator yoke and in the stator teeth. The variables Ti correspond to the temperatures at different points of the machine. The terms of thermal resistances are deduced from the resolution of the heat equation border areas.

\subsection{Calculation of Conduction Resistances}

For the sake of simplification, the conduction along the transverse axis of the stator is not taken although it may be essential, especially in the windings. Heat transfer in a stator element therefore allows one preferred direction, the axial direction. This is reflected by the following heat equation [1].

$$
\frac{\overrightarrow{\Phi_{\mathrm{T}}}}{\mathrm{S}_{\mathrm{et}}}=-\lambda \times \overrightarrow{\operatorname{grad} T}=-\lambda \times \frac{\mathrm{T}_{1}-\mathrm{T}_{2}}{\mathrm{x}_{1}-\mathrm{x}_{2}} \overrightarrow{\mathrm{x}}
$$

Equation 2 can be derived from a general formula of thermal conduction resistance to an axial flux distribution:

$$
\mathrm{R}=\frac{\mathrm{E}}{\lambda \times \mathrm{S}_{\mathrm{et}}}
$$

Where $\lambda$ is the thermal conductivity, $S_{\text {et }}$ is the heat exchange section and $\Phi_{\mathrm{T}}$ is the total heat flux exchanged and $\mathrm{E}$ is the thickness of the heat exchange.

The conduction resistances can be deduced from the geometrical equations of PMSM and CRSM.

For PMSM structures, the conduction resistances of the materials constituting the rotor are expressed by the following relationships:

- The conduction resistance of the rotor yoke is expressed by the following relationship:

$$
\mathrm{R}_{\mathrm{cr}}=\frac{\mathrm{H}_{\mathrm{cr}}}{\lambda_{\mathrm{fer}} \times\left(\pi \times \frac{\mathrm{D}_{\mathrm{e}}^{2}-\mathrm{D}_{\mathrm{i}}^{2}}{4}\right)}
$$

Where $\lambda_{\text {fer }}$ is the thermal conductivity of the iron, $\mathrm{H}_{\mathrm{cr}}$ is the rotor yoke thikness, $\mathrm{D}_{\mathrm{e}}$ and $\mathrm{D}_{\mathrm{i}}$ are respectively the exetrnel and internal diameter of the motor.

- The conduction resistance of the magnet is expressed by the following relationship:

$$
\begin{aligned}
& \mathrm{R}_{\text {caim }}=\frac{\mathrm{H}_{\mathrm{a}}}{\lambda_{\mathrm{a}} \times 2 \times \mathrm{p} \times \mathrm{S}_{\mathrm{a}}}(4) \\
& \mathrm{R}_{\text {cisor }}=\frac{\left(1-\mathrm{K}_{\mathrm{f}}\right) \times \mathrm{N}_{\mathrm{sr}} \times \mathrm{I}_{\mathrm{e}}}{\lambda_{\text {iso }} \times\left(\mathrm{L}_{\mathrm{er}} \times\left(\mathrm{E}_{\mathrm{cs}}+\mathrm{L}_{\mathrm{er}} \times 2\right) \times 2+2 \times\left(\left(\frac{\mathrm{D}_{\mathrm{e}}+\mathrm{D}_{\mathrm{i}}}{4}\right) \times \mathrm{L}_{\mathrm{p}} \times \frac{2}{3}\right) \times \mathrm{L}_{\mathrm{er}}\right) \times 2 \times \mathrm{p}}
\end{aligned}
$$

Where $\lambda_{\mathrm{a}}$ is thermal conductivity of the magnets, $\mathrm{p}$ is the nomber of pole pairs, $\mathrm{S}_{\mathrm{a}}$ is the magnet section and $\mathrm{H}_{\mathrm{a}}$ is magnet thikness.

- The conduction resistance of the air-gap is expressed by the following relationship:

$$
\mathrm{R}_{\text {cen }}=\frac{\mathrm{e}}{\lambda_{\text {air }} \times\left(\pi \times \frac{\mathrm{D}_{\mathrm{e}}^{2}-\mathrm{D}_{\mathrm{i}}^{2}}{4}\right)}
$$

Where $\lambda_{\text {air }}$ is the thermal conductivity of air and e is the air-gap thikness.

For CRSM structures, the conduction resistances of the materials constituting the rotor are expressed by the following relationships:

- The conduction resistance of the copper rotor is expressed by the following relationship:

$$
\mathrm{R}_{\text {crr }}=\frac{\frac{\mathrm{N}_{\mathrm{sr}} \times \mathrm{I}_{\mathrm{e}}}{\delta \times \mathrm{L}_{\mathrm{p}} \times \frac{1}{6} \times \frac{\left(\mathrm{D}_{\mathrm{e}}+\mathrm{D}_{\mathrm{i}}\right)}{4}}}{\lambda_{\text {fer }} \times\left(\mathrm{L}_{\mathrm{er}} \times\left(\mathrm{E}_{\mathrm{cs}}+\mathrm{L}_{\mathrm{er}} \times 2\right) \times 2+2 \times\left(\left(\frac{\mathrm{D}_{\mathrm{e}}+\mathrm{D}_{\mathrm{i}}}{4}\right) \times \mathrm{L}_{\mathrm{p}} \times \frac{2}{3}\right) \times \mathrm{L}_{\mathrm{er}}\right) \times 2 \times \mathrm{p}}
$$

Where $L_{e r}$ is the width of a rotor slot:

$$
\mathrm{L}_{\mathrm{er}}=\mathrm{L}_{\mathrm{p}} \times \frac{1}{6} \times\left(\frac{\mathrm{D}_{\mathrm{e}}+\mathrm{D}_{\mathrm{i}}}{4}\right)
$$

and $\mathrm{E}_{\mathrm{cs}}$ is equal to:

$$
E_{c s}=\left(\frac{D_{e}-D_{i}}{2}\right)
$$

$\mathrm{L}_{\mathrm{p}}$ is the polar pitch :

$$
\mathrm{L}_{\mathrm{p}}=\frac{\pi}{\mathrm{p}}
$$

The conduction resistance of the rotor teeth is expressed by the following relationship:

$$
\mathrm{R}_{\mathrm{cdr}}=\frac{\frac{\mathrm{N}_{\mathrm{sr}} \times \mathrm{I}_{\mathrm{e}}}{\delta \times \mathrm{L}_{\mathrm{p}} \times \frac{1}{6} \times \frac{\left(\mathrm{D}_{\mathrm{e}}+\mathrm{D}_{\mathrm{i}}\right)}{4} \times \mathrm{K}_{\mathrm{f}}}}{\lambda_{\text {fer }} \times \mathrm{L}_{\mathrm{p}} \times \frac{2}{3} \times\left(\frac{\mathrm{D}_{\mathrm{e}}+\mathrm{D}_{\mathrm{i}}}{4}\right) \times \mathrm{E}_{\mathrm{cs}} \times 2 \times \mathrm{p}}
$$

- The conduction resistance of the rotor insulation is expressed by the following relationship: 
Where $\lambda_{\text {iso }}$ is the thermal conductivity of insulation and $K_{f}$ is load factor of slots.

- The conduction resistance of the rotor yoke is expressed by the following relationship:

$$
\mathrm{R}_{\mathrm{ccr}}=\frac{\mathrm{H}_{\mathrm{cr}}}{\lambda_{\mathrm{fer}} \times \pi \times\left(\frac{\mathrm{D}_{\mathrm{e}}^{2}-\mathrm{D}_{\mathrm{i}}^{2}}{4}\right)}
$$

We recall that for both structures, the stator structure is the same. The conduction resistances respectively of the coils $\left(\mathrm{R}_{\mathrm{cu})}\right.$, insulation $\left(\mathrm{R}_{\mathrm{iso}}\right)$ of main teeth $\left(\mathrm{R}_{\mathrm{cd}}\right)$ and stator yoke $\left(\mathrm{R}_{\mathrm{cs}}\right)$

$$
\mathrm{R}_{\text {iso }}=\frac{\left(1-\mathrm{K}_{\mathrm{f}}\right) \times \mathrm{H}_{\mathrm{d}}}{\lambda_{\text {iso }} \times \mathrm{N}_{\mathrm{d}} \times\left(2 \times \mathrm{L}_{\mathrm{enc}} \times \frac{\mathrm{D}_{\mathrm{e}}-\mathrm{D}_{\mathrm{i}}}{2}+\frac{\mathrm{D}_{\mathrm{i}}}{2} \times \mathrm{A}_{\text {dent } 1} \times \mathrm{L}_{\mathrm{enc}}+\frac{\mathrm{D}_{\mathrm{e}}}{2} \times \mathrm{A}_{\text {dent } 2} \times \mathrm{L}_{\mathrm{enc}}\right)}
$$

Where $\lambda_{\text {iso }}$ is the thermal conductivity of the insulation, $\mathrm{A}_{\text {dent1 }}$ the lower main tooth angle, $\mathrm{A}_{\text {dent2 }}$ is higher angle of the

The slot width $\mathrm{L}_{\mathrm{enc}}$ is expressed as follows:

$$
\mathrm{L}_{\mathrm{enc}}=\mathrm{B} \sin \left(\frac{1}{2}\left(\frac{2 \pi}{\mathrm{N}_{\mathrm{d}}}-\alpha \beta \frac{\pi}{\mathrm{p}}\left(1-\mathrm{r}_{\mathrm{did}}\right)\right)\right)
$$

Where $r_{\text {did }}$ is the ratio between the angular width of the inserted tooth and that of the principal tooth. This ratio is optimised by finite elements simulations in order to reduce the flux leakages and to improve the back electromotiv force wave-form.

Where $\mathrm{B}$ is equal to :

$$
\mathrm{B}=\frac{\mathrm{D}_{\mathrm{e}}+\mathrm{D}_{\mathrm{i}}}{2}
$$

The PMSM and CRSM configuration is caracterized by variation law of the pole pairs number (p) according to an integer number $n$ varying from one to infinity, the ratio $(r)$ of the number of principal teeth $\left(\mathrm{N}_{\mathrm{d}}\right)$ by the number of pole pairs, the ratio $(v)$ between the angular width between two principal teeth and that of a principal tooth, the ratio $(\alpha)$ between the angular width of a principal tooth and that of a magnet and the ratio $(\beta)$ between the angular width of a magnet and the polar step.

The conduction resistance of the main teeth is expressed by the following relationship:

$$
\mathrm{R}_{\mathrm{cd}}=\frac{\mathrm{H}_{\mathrm{d}}}{\lambda_{\text {fer }} \times\left(\mathrm{N}_{\mathrm{d}} \times \mathrm{S}_{\mathrm{d}}\right)}
$$

Where $\mathrm{H}_{\mathrm{d}}$ is the teeth high, $\mathrm{S}_{\mathrm{d}}$ is the main tooth section.

- The conduction resistance of the stator yoke is expressed by the following relationship:

$$
\mathrm{R}_{\mathrm{cs}}=\frac{\mathrm{H}_{\mathrm{cs}}}{\lambda_{\mathrm{fer}} \times\left(\pi \times \frac{\mathrm{D}_{\mathrm{e}}^{2}-\mathrm{D}_{\mathrm{i}}^{2}}{4}\right)}
$$
main tooth, $\mathrm{N}_{\mathrm{d}}$ is the tooth number. for the two structures are equal.

- The conduction resistance of the coils is expressed by the following relationship:

$$
\mathrm{R}_{\mathrm{cu}}=\frac{\mathrm{K}_{\mathrm{f}} \times \mathrm{H}_{\mathrm{d}}}{\lambda_{\mathrm{c}} \times \mathrm{N}_{\mathrm{d}} \times\left(2 \times \mathrm{L}_{\mathrm{enc}} \times \frac{\mathrm{D}_{\mathrm{e}}-\mathrm{D}_{\mathrm{i}}}{2}+\frac{\mathrm{D}_{\mathrm{i}}}{2} \times \mathrm{A}_{\text {dent }} \times \mathrm{L}_{\text {enc }}+\frac{\mathrm{D}_{\mathrm{e}}}{2} \times \mathrm{A}_{\text {dent } 2} \times \mathrm{L}_{\mathrm{enc}}\right)}
$$

Where $\lambda_{c}$ is the thermal conductivity of copper and $H_{d}$ is the stator tooth high.

- The conduction resistance of the insulator is expressed by the following relationship:
Wher $\mathrm{H}_{\mathrm{cs}}$ is the stator yoke thikness.

- The conduction resistance of the air between two modules is expressed as follows:

$$
\mathrm{R}_{\mathrm{Air}}=\frac{\mathrm{E}_{\mathrm{air}}}{\lambda_{\text {air }} \times \frac{\pi \times \mathrm{D}_{\mathrm{e}}^{2}}{4}}
$$

Where $\mathrm{E}_{\text {air }}$ is the thickness of air between two modules.

- The conduction resistance of the flanges is expressed as follows:

$$
\mathrm{R}_{\mathrm{fls}}=\mathrm{R}_{\mathrm{flr}}=\frac{\mathrm{E}_{\mathrm{fl}}}{\lambda_{\mathrm{fer}} \times \frac{\pi \times \mathrm{D}_{\mathrm{e}}^{2}}{4}}
$$

Where $\mathrm{E}_{\mathrm{fl}}$ is the thickness of the flanges.

\subsection{Convection Resistances Computation}

The convective heat transfer is the preferred mode of transfer within the fluids. Then it is generally much more important than conduction. We must distinguish between natural convection and forced convection.

Density differences related to differences in temperature cause movements of the fluid which is heated in contact with hot body and thus carries the heat to colder areas: the natural convection. The yoke and the outer flanges of the machine in the absence of external fan, undergo this transfer mode. In the internal parts, not brewed areas are rare due to the rotor. The heat exchange coefficient between the housing and the ambient air, can be between 20 and $50 \mathrm{~W} \cdot \mathrm{K}^{-1} \cdot \mathrm{m}^{-2}$ for machine natural ventilation and can exceed $80 \mathrm{~W} . \mathrm{K}^{-1} \cdot \mathrm{m}^{-2}$ for machines with forced ventilation.

The only network element that refers to a transfer by convection is $R_{\text {ext }}$, which represents the overall thermal resistance between the surface of the casing, the flanges and the ambient air.

$$
\operatorname{Rex}=\frac{1}{h \cdot S_{s}}=\frac{1}{h \cdot S_{r}}
$$


Where $h$ is the heat transfer coefficient, $S_{s}$ is the area of heat exchange with the stator and $S_{r}$ is the area of heat exchange with the rotor.

The calculation of external surface of the actuator requires some remarks. Should we consider only the side surfaces (flanges) of the machine or also include the outer surface of the cylinder? Model assumptions, namely a consideration of phenomena only in the axial axis, incite choose the first solution. Wherein the surfaces of heat exchange by convection are expressed by the following relationship:

$$
\mathrm{S}_{\mathrm{s}}=\mathrm{S}_{\mathrm{r}}=\pi \times \frac{\mathrm{D}_{\mathrm{e}}^{2}}{4}
$$

\subsection{Calculation of Thermal Capacity}

We will study the thermal phenomena of a transient point of view, it is therefore necessary to involve the heat capacities of the materials constituting the components of the machine.

The terms of thermal capacity is calculated from the following relationship between the mass of materials and their massive heat capacity using the following equation [6] and [7]:

$$
\mathrm{C}=\rho \times \mathrm{V} \times \mathrm{c}=\mathrm{M} \times \mathrm{c}
$$

With $\rho$ is the density of the material, $\mathrm{V}$ is the volume of the material, $\mathrm{c}$ is the mass heat capacity of the material and $\mathrm{M}$ is the mass of the material.

\subsection{Heat Flux}

The heat flux $\Phi_{1}$ corresponds to iron losses in the stator yoke $\left(\mathrm{P}_{\mathrm{fc}}\right)$. This flux propagates from the center of gravity of the stator yoke. It is expressed by the following equation [8]:

$$
\Phi_{1}=\mathrm{P}_{\mathrm{fc}}=\mathrm{q} \times \mathrm{f}^{1.5} \times \mathrm{M}_{\mathrm{cs}} \times \mathrm{B}_{\mathrm{cs}}^{2}
$$

Where $\mathrm{q}$ is the quality factor of the metal sheets, $\mathrm{M}_{\mathrm{cs}}$ is the mass of the stator yoke and $\mathrm{B}_{\mathrm{cs}}$ is the magnetic induction in the stator yoke.

The heat flux $\Phi_{2}$ corresponds to the iron losses in the stator yoke $\left(\mathrm{P}_{\mathrm{fd}}\right.$. This flux propagates from the center of gravity of the stator teeth. It is expressed by the following equation [8]:

$$
\Phi_{2}=\mathrm{P}_{\mathrm{fd}}=\mathrm{q} \times \mathrm{f}^{1.5} \times \mathrm{M}_{\mathrm{ds}} \times \mathrm{B}_{\mathrm{d}}^{2}
$$

Where $M_{d s}$ is the mass of the stator teeth and $B_{d}$ is the magnetic induction in the stator teeth.

The heat flux $\Phi_{3}$ corresponds to the copper losses in the stator $\left(\mathrm{P}_{\mathrm{j}}\right)$. This flux propagates from the center of gravity of the stator copper. It is expressed by the following equation:

$$
\Phi_{3}=\mathrm{P}_{\mathrm{j}}=\frac{3}{2} \times \mathrm{R} \times \mathrm{I}^{2}
$$

Where $\mathrm{R}$ is the resistance of the stator winding, it is expressed by the following relationship:

$$
\mathrm{R}=\frac{\mathrm{r}_{\mathrm{cu}} \times \mathrm{N}_{\mathrm{s}} \times \mathrm{L}_{\mathrm{sp}}}{\frac{\mathrm{C}_{\mathrm{dim}}}{\sqrt{2} \times \delta \times \mathrm{K}_{\mathrm{e}}}}
$$

Where $r_{c u}$ is the resistivity of copper, $L_{s p}$ is the average length of one turn, $\mathrm{N}_{\mathrm{s}}$ is the number of phase spires, $\mathrm{C}_{\mathrm{dim}}$ is the dimensionnig torque of the motor, $\delta$ is the current density in the copper and $\mathrm{K}_{\mathrm{e}}$ is the back electromotive force constant.

$$
\begin{aligned}
\mathrm{L}_{\mathrm{sp}}= & \left(\mathrm{A}_{\text {dent } 1}+\mathrm{A}_{\text {enc1 }}\right) \times\left(\frac{\mathrm{D}_{\mathrm{i}}}{2}-\frac{\mathrm{L}_{\mathrm{enc}}}{2}\right)+\left(\mathrm{A}_{\text {dent } 2}+\mathrm{A}_{\mathrm{enc} 2}\right) \\
& \times\left(\frac{\mathrm{D}_{\mathrm{e}}}{2}-\frac{\mathrm{L}_{\mathrm{enc}}}{2}\right)+2 \times\left(\left(\frac{\mathrm{D}_{\mathrm{e}}-\mathrm{D}_{\mathrm{i}}}{2}\right)+\mathrm{L}_{\mathrm{enc}}\right)
\end{aligned}
$$

For CRSM structure the flux $\Phi_{4}$ corresponds to rotor copper losses $\left(\mathrm{P}_{\mathrm{jr})}\right.$. This flux propagates from the center of gravity of the rotor copper, it is expressed by the following equation:

$$
\Phi_{4}=\mathrm{R}_{\mathrm{e}} \times \mathrm{I}_{\mathrm{e}}^{2}
$$

Where $R_{e}$ is the resistance of the rotor winding, is expressed by the following relationship:

$$
\mathrm{R}_{\mathrm{e}}=\frac{2 \times \mathrm{p} \times \mathrm{r}_{\mathrm{cu}} \times \mathrm{N}_{\mathrm{sb}} \times \mathrm{L}_{\mathrm{sp}}}{\frac{\mathrm{I}_{\mathrm{e}}}{\delta}}
$$

where $\mathrm{N}_{\mathrm{Sb}}$ is the number of conductors of the rotor winding, $\mathrm{I}_{\mathrm{e}}$ is the excitation current and $\mathrm{L}_{\mathrm{msr}}$ is the average length of a rotor coil:

$$
\mathrm{L}_{\mathrm{msr}}=2 \times\left(\left(\frac{\mathrm{D}_{\mathrm{e}}-\mathrm{D}_{\mathrm{i}}}{2}\right)+\mathrm{L}_{\mathrm{er}}\right)+\left(\left(\frac{\mathrm{D}_{\mathrm{e}}+\mathrm{D}_{\mathrm{i}}}{4}\right) \times \mathrm{L}_{\mathrm{p}} \times \frac{2}{3}+2 \times \mathrm{L}_{\mathrm{er}}\right)
$$

\section{Results of Simulations}

The loss model for both PMSM and CRSM structures for an electromagnetic switch power chain is located under the environment of Matlab / Simulink. Heat fluxes are calculated based on the inverse modeling approach of the power chain (figure 7).

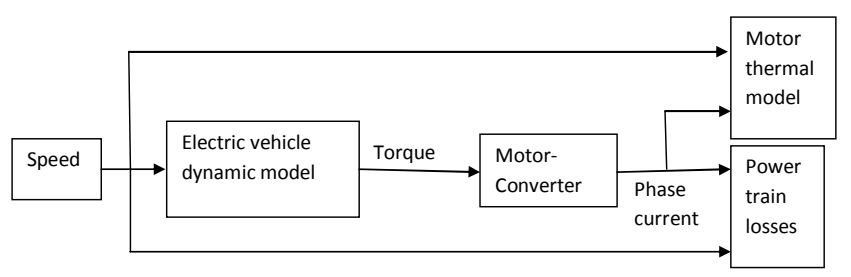

Figure 7. Electric vehicle power train model.

Simulation results are obtained for the standard travels (1027 s) during repeated over a period of $200000 \mathrm{~s}$ (Figure 8). 


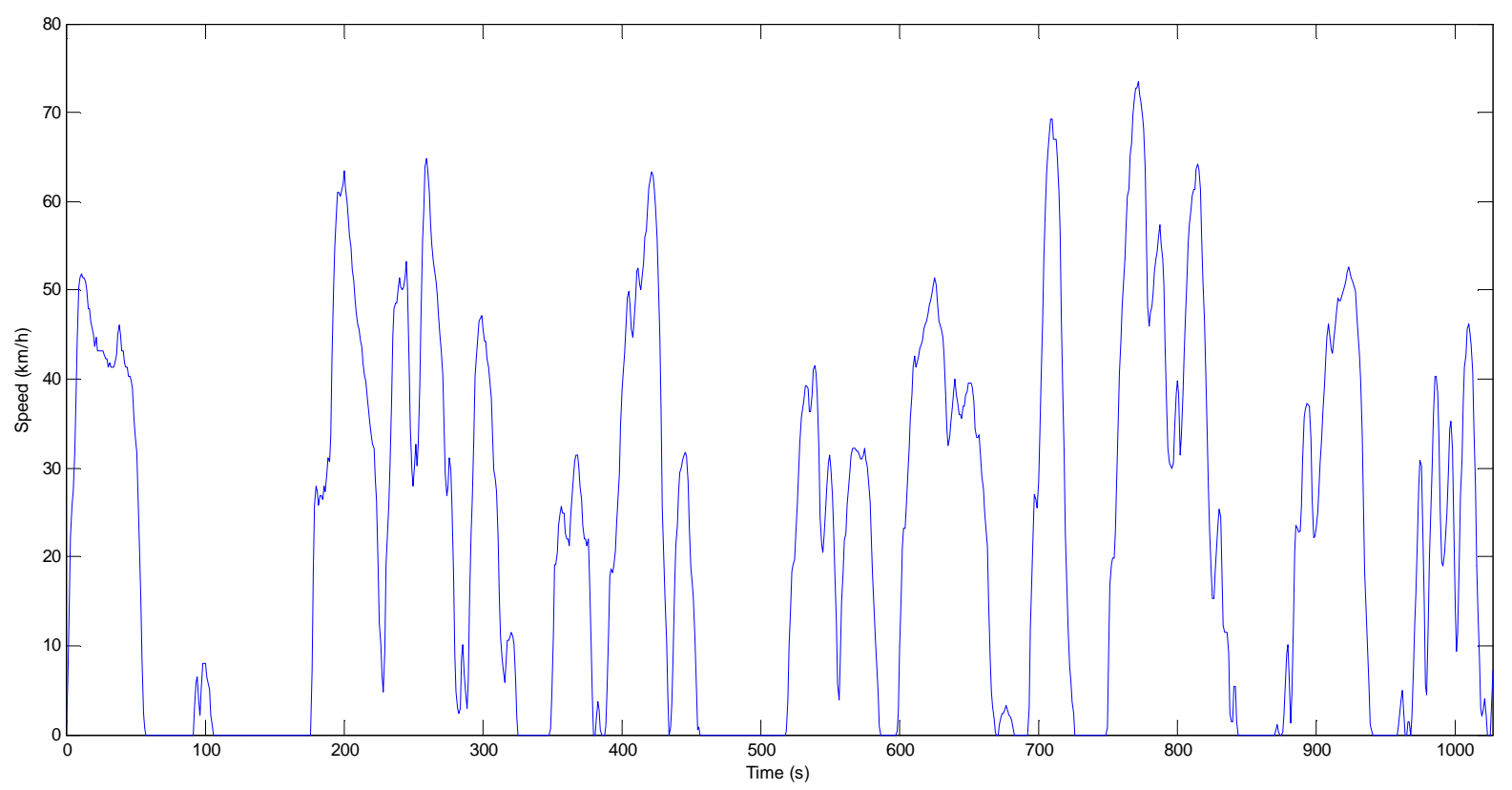

Figure 8. Standardized travels.

\subsection{PMSM Structure}

The simulation of the thermal model of the PMSM structure, with natural convection with air (convection coefficient equal to $\left.30 \mathrm{~W} /\left(\mathrm{m}^{2} \cdot \mathrm{K}\right)\right)$, shows the evolution of temperatures in different active parts of the motor (figure 9).

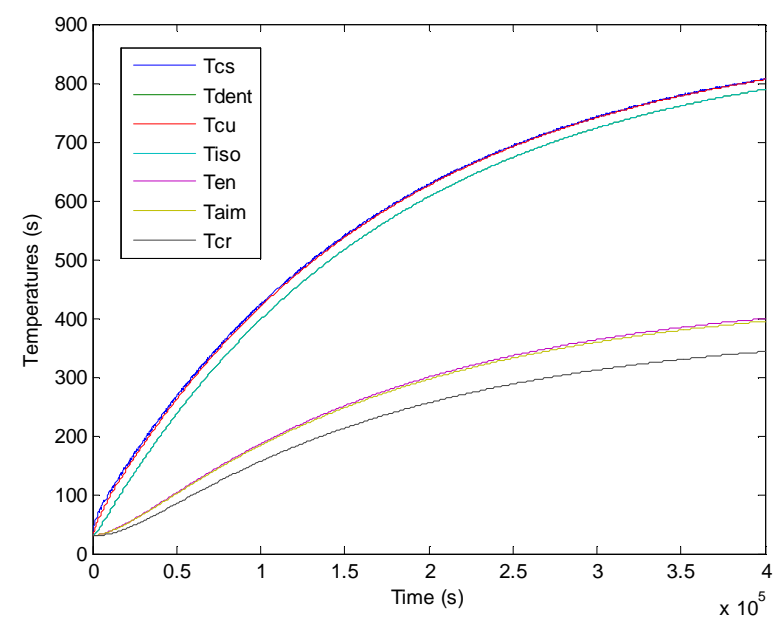

Figure 9. Evolution of temperatures in the different active parts of the motor $\left(h=30 \mathrm{~W} /\left(\mathrm{m}^{2} . K\right)\right)$.

Where $\mathrm{Tfl}$ is the average temperature of the flanges, Tcr is the average temperature of the rotor yoke, Taim is the average temperature of magnets, Ten is the average temperature of the air gap, Tiso is the average temperature of the insulation, Tcu is the average temperature of the copper, Tdent is the average temperature of the stator teeth and $\mathrm{Tc}$ is the average temperature of the stator yoke .

This figure shows that there's an exceeding of $700{ }^{\circ} \mathrm{C}$ for the resin, which proves the need for a cooling system. Several simulations are undertaken for several values of coefficient of forced convection in water, have led to the fixing of this coefficient to $5000 \mathrm{~W} /\left(\mathrm{m}^{2} . \mathrm{K}\right)$.

Evolutions of temperature in the different active parts of the engine for operation with a cooling system with forced convection in water $\left(\mathrm{h}=5000 \mathrm{~W} /\left(\mathrm{m}^{2} . \mathrm{K}\right)\right)$ is illustrated in figure 10 .

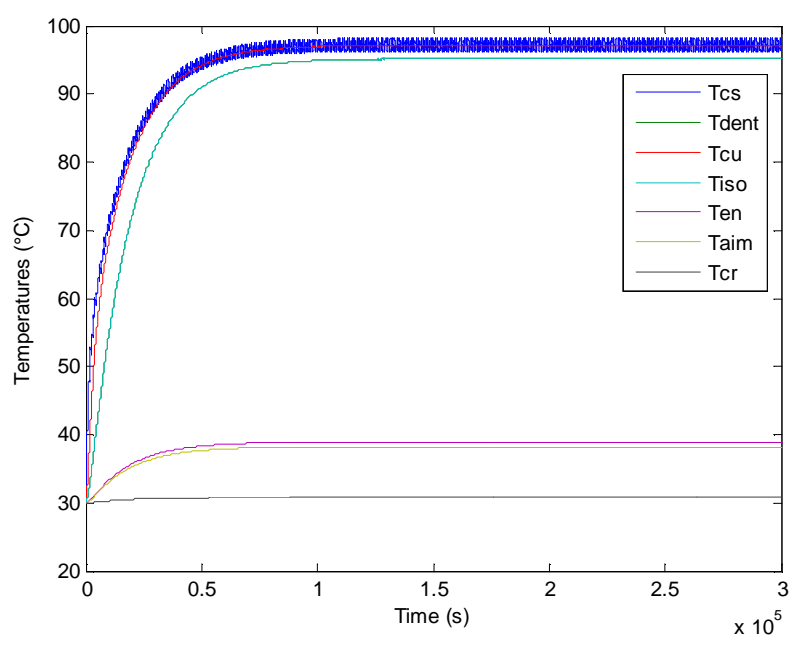

Figure 10. Evolution of temperatures in the different active parts of the motor $\left(h=5000 \mathrm{~W} /\left(\mathrm{m}^{2} . K\right)\right)$.

This figure shows that the temperature of the insulation is reduced to $90^{\circ} \mathrm{C}$, acceptable value.

\subsection{CRMS Structure}

The simulation of the thermal model of the CRSM structure, with natural convection with air (convection coefficient equal to $\left.30 \mathrm{~W} /\left(\mathrm{m}^{2} . \mathrm{K}\right)\right)$, shows the evolution of temperatures in different active parts of the motor (Figure 11).

Where $\mathrm{Tfl}$ is the average temperature of the flanges, Tcr is the average temperature of the rotor yoke, Tdentr is the average temperature of the rotor teeth, Tcur is the average 
temperature of the rotor copper, Ten is the average temperature of the air gap, Tiso is average temperature of the insulation, Tcu is the average temperature of the stator copper, Tdent is the average temperature of the stator teeth and Tcs is the average temperature of the stator yoke .

This figure shows that there's an exceeding of $1400^{\circ} \mathrm{C}$ for the resin, which proves the need for a cooling system. Simulations are launched for same value of convection coefficient for a forced cooling system thein PMSM structure $\left(5000 \mathrm{~W} /\left(\mathrm{m}^{2} . \mathrm{K}\right)\right)$ leds to the evolutions of temperature in the different active parts of the engine figure 12 .

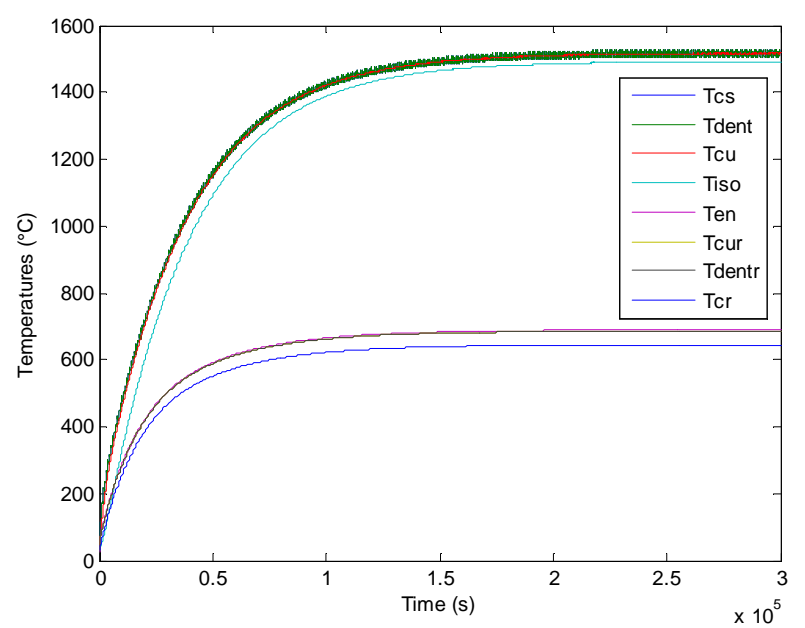

Figure 11. Evolution of temperatures in the different active parts of the motor $\left(h=30 \mathrm{~W} /\left(\mathrm{m}^{2} \cdot \mathrm{K}\right)\right)$.

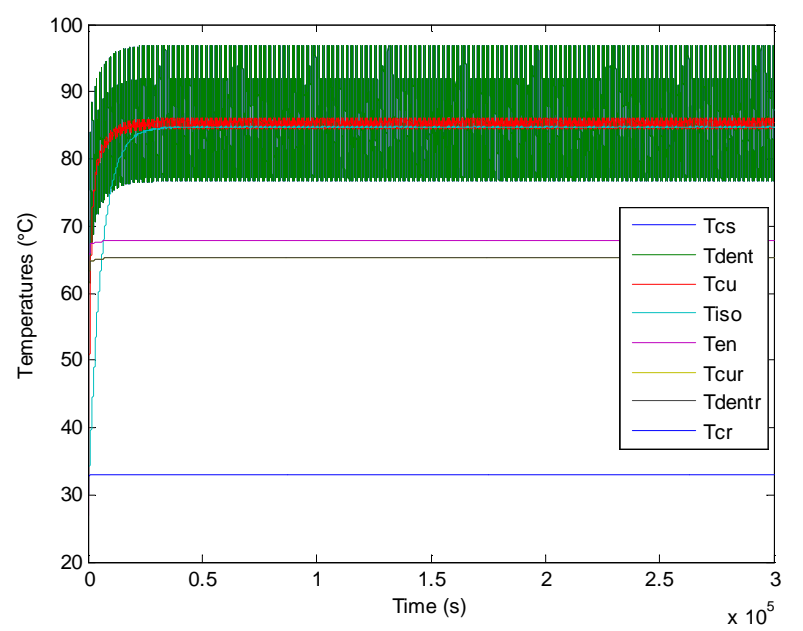

Figure 12. Evolution of temperatures in the different active parts of the motor $\left(h=5000 \mathrm{~W} /\left(\mathrm{m}^{2} \cdot \mathrm{K}\right)\right)$.

This figure shows that the temperatures of copper and insulation are reduced to $84^{\circ} \mathrm{C}$, acceptable value for a good functionning of engine.

\subsection{Comparison between the Two Structures Engine}

Thermal analysis relied on the nodal thermal models of both PMSM and CRSM structures shows that for the same functionning mode and for the same stator, the components of a CRSM structure heats more than the components of a
PMSM structure. This property is justified by the fact that the CRSM structure has additional rotor copper losses. Accordingly, the PMSM structure system requires the least powerful cooling system and the less expensive. This structure is chosen for further study.

\section{Conclusion}

In this paper we present a methodology for electrothermal modeling of two engine configurations, one with permanent magnet and the other with wound rotor to select the configuration compatible with the less powerful and the least expensive cooling system. This approach is based on modeling with nodal method because it provides a fast and acceptable precision for our application, it is integrable to optimization approaches of the design parameters of electric cars. This study has led to the choice of the configuration with permanent magnet since the simulation results show that the cooling system to be integrated to this configuration is the less powerful and less expensive by the following.

\section{List of Symbols}

$\mathrm{C}_{\mathrm{flr}} \quad$ Rotor flanges capacity

$\mathrm{C}_{\mathrm{cr}} \quad$ Rotor yoke capacity

$\mathrm{C}_{\text {aim }} \quad$ Magnet capacity

$\mathrm{C}_{\mathrm{en}} \quad$ Air-gap capacity

$\mathrm{C}_{\text {iso }} \quad$ Insulation capacity

$\mathrm{C}_{\mathrm{cu}} \quad$ Copper capacity

$\mathrm{C}_{\mathrm{d}} \quad$ Teeth capacity

$\mathrm{C}_{\mathrm{cs}} \quad$ Stator yoke capacity

$\mathrm{C}_{\text {Air }} \quad$ Air capacity

$\mathrm{C}_{\mathrm{fls}} \quad$ Stator flanges capacity

$\mathrm{P}_{\mathrm{j}} \quad$ Copper losses of stator

$\mathrm{P}_{\mathrm{fd}} \quad$ Iron losses of stator teeth

$\mathrm{P}_{\mathrm{fc}} \quad$ Iron losses of stator yoke

$\mathrm{T}_{\text {flr }}$

$\mathrm{T}_{\mathrm{cr}}$

$\mathrm{T}_{\text {aim }}$

$\mathrm{T}_{\mathrm{en}}$

$\mathrm{T}_{\text {iso }}$

$\mathrm{T}_{\mathrm{cu}}$

$T_{\text {dent }}$

$\mathrm{T}_{\mathrm{cs}}$

$\mathrm{T}_{\text {Air }}$

$\mathrm{T}_{\text {fls }}$

$\mathrm{T}_{\mathrm{a}}$

$\mathrm{R}_{\mathrm{flr}}$

$\mathrm{R}_{\mathrm{cr}}$

$\mathrm{R}_{\text {aim }}$

$\mathrm{R}_{\mathrm{en}}$

$\mathrm{R}_{\text {iso }}$

$\mathrm{R}_{\mathrm{cu}}$

$\mathrm{R}_{\mathrm{cd}}$

$\mathrm{R}_{\mathrm{cs}}$

$\mathrm{R}_{\text {Air }}$ Average temperature of rotor flanges Average temperature of rotor yoke Average temperature of magnet Average temperature of air-gap Average temperature of stator Insulation Average temperature of stator copper Average temperature of stator teeth Average temperature of stator yoke Average temperature of air Average temperature of stator flanges Ambient temperature

Thermal conduction resistance of rotor flanges Thermal conduction resistance of rotor yoke Thermal conduction resistance of magnet Thermal conduction resistance of air-gap Thermal conduction resistance of of Insulation Thermal conduction resistance of stator copper Thermal conduction resistance of teeth Thermal conduction resistance of stator yoke Thermal conduction resistance of air

$\mathrm{R}_{\mathrm{fls}} \quad$ Thermal conduction resistance of stator flanges 


$\begin{array}{ll}\mathrm{C}_{\mathrm{cr}} & \text { Capacity of rotor copper } \\ \mathrm{C}_{\mathrm{dr}} & \text { Capacity of rotor teeth } \\ \mathrm{C}_{\mathrm{ccr}} & \text { Capacity of rotor yoke } \\ \mathrm{C}_{\mathrm{isor}} & \text { Capacity of rotor insulation } \\ \mathrm{T}_{\text {dentr }} & \text { Average temperature of rotor teeth } \\ \mathrm{T}_{\text {isor }} & \text { Average temperature of rotor insulation } \\ \mathrm{T}_{\text {cur }} & \text { Average temperature of rotor copper } \\ \mathrm{R}_{\mathrm{ccr}} & \text { Thermal conduction resistance of rotor yoke } \\ \mathrm{R}_{\mathrm{cdr}} & \text { Thermal conduction resistance of rotor teeth } \\ \mathrm{R}_{\mathrm{cisor}} & \text { Thermal conduction resistance of rotor insulation } \\ \mathrm{R}_{\text {cur }} & \text { Thermal conduction resistance of rotor copper } \\ \mathrm{P}_{\mathrm{jr}} & \text { Rotor copper losses } \\ \mathrm{h} & \text { Coefficient of thermal convection }\end{array}$

\section{References}

[1] S. TOUNSI et R. NEJI: «Design of an Axial Flux Brushless DC Motor with Concentrated Winding for Electric Vehicles», Journal of Electrical Engineering (JEE), Volume 10, 2010 Edition: 2, pp. 134-146.

[2] A. AMMOUS, B. ALLARD, H. MOREL: «Transient temperature mesurements and modeling of IGBT's under short circuit», IEEE transaction electronic devices, vol. $13, \mathrm{n}^{\circ} 1$, 1998, p. 12-25.
[3] S.TOUNSI, R.NÉJI, F.SELLAMI : « Conception d'un actionneur à aimants permanents pour véhicules électriques ", Revue Internationale de Génie Électrique volume 9/6 2006 pp.693-718.

[4] Tounsi S., Neji R., Sellami F., « Modélisation des pertes dans la chaîne de traction du véhicule électrique », CTGE 2004, 19-21 Février, Tunis, Tunisie, p. 291-297.

[5] M.A.FAKHFAKH, M. HADJ KASEM, S. TOUNSI et R. NEJI: «Thermal Analysis of Permanent Magnet Synchronous Motor for Electric Vehicle», Journal of Asian Electric Vehicles, volume 6, Number 2, December 2008, pp. 1145-1151.

[6] S. MEZANI, «Modélisation électromagnétique et thermique des moteurs à induction, en tenant compte des harmoniques d'espace ». Thèse de doctorat, Institut National polytechnique de LORRAINE, 2004.

[7] Q.Pan et A. Razek, "Phénomènes magnéto-thermiques dans les machines asynchrones à cage. Analyse par éléments finis », Revue Générale de Thermique, n³48, pp. 720-726, décembre 1990.

[8] R. NEJI, S. TOUNSI et F. SELLAMI: «Contribution to the definition of a permanent magnet motor with reduced production cost for the electrical vehicle propulsion», European Transactions on Electrical Power (ETEP), 2006, 16: pp. 437-460. 